\title{
ANÁLISE DE INVESTIMENTOS EM AÇÕES AMBIENTAIS EM OFICINA MECÂNICA
}

\author{
Investment analysis on environmental actions in mechanical workshop \\ Análisis de inversión en acciones ambientales en oficina mecanica
}

RONALDO JOSÉ SERAMIM Acadêmico do Mestrado Profissional em Administração da Unioeste

TAMARA

PEREIRA ZANELLA Acadêmica do Mestrado

Profissional em Administração da Unioeste

MARIA DA PIEDADE ARAUJO Docente do Mestrado em Contabilidade da Unioeste. Doutora em Economia.

GEYSLER ROGIS FLOR BERTOLINI Docente do Mestrado Profissional em Administração, e do Mestrado em Desenv. Rural Sustentável da Unioeste. Doutor em Engenharia de Produção.

Submetido 16.12.2015.

Aprovado 26.07.2016 Avaliado pelo processo de double blind review.

\section{RESUMO}

Este trabalho discute a viabilidade de investimentos em ações dedicadas ao cuidado com o meio ambiente, dentro dos aspectos da sustentabilidade. O objetivo é analisar a viabilidade de investimentos em ações ambientais em oficina mecânica do oeste do Paraná. A análise considera os investimentos necessários para adequar uma oficina mecânica para além das exigências legais e sua perspectiva de retorno. A metodologia de pesquisa é descritiva, com abordagem qualitativa e quantitativa. Os dados foram coletados por meio de entrevista e questionário com 51 clientes potenciais. A análise de viabilidade foi baseada no modelo adaptado de Bertolini et al. (2012). Ao final foi possível concluir sobre a viabilidade, a partir da disposição dos consumidores em pagar mais pelos serviços em uma oficina mecânica que agrege valor ao serviço utilizando-se de práticas ambientalmente sustentáveis.

Palavras-chave: Sustentabilidade. Meio ambiente. Viabilidade de investimentos. Oficina mecânica.

\section{ABSTRACT}

This paper discusses the feasibility of investments in actions dedicated to caring for the environment, within the areas of sustainability. Therefore, the goal is to analyze the feasibility of investments in environmental actions in a mechanical workshop of western Paraná State. The analysis considers the investments needed to adapt a mechanical workshop to beyond legal requirements and its return perspective. The research methodology is descriptive with a qualitative and quantitative approach. Data were collected through interviews and questionnaire with 51 potential customers. The feasibility analysis was based on the adapted model of Bertolini et al. (2012). At the end, it was concluded on the feasibility, from the willingness of consumers to pay more for services in a mechanical workshop that adds value to the service using environmentally sustainable practices.

Keywords: Sustainability. Environment. Feasibility of investment.; Mechanical workshop.

\section{RESUMEN}

En este trabajo se analiza la viabilidad de las inversiones en acciones dedicadas al cuidado del medio ambiente dentro de las áreas de la sostenibilidad. El objetivo es analizar la viabilidad de las inversiones en acciones ambientales en oficina mecánico oeste de Paraná. El análisis considera las inversiones necesarias para adaptar una oficina mecánica allá de los requisitos legales y su perspectiva de retorno. La metodología de investigación es descriptiva con enfoque cualitativo y cuantitativo. Los datos fueron recolectados a través de entrevistas y un cuestionario con 51 clientes potenciales. El análisis de factibilidad se basó en el modelo adaptado Bertolini et al. (2012). Al final se concluyó sobre la viabilidad, de la voluntad de los consumidores a pagar más por los servicios en un taller mecánico que agrégé valor al servicio usando prácticas ambientalmente sostenibles.

Palabras clave: Sostenibilidad. Medio ambiente. Viabilidad de las inversiones. Oficina mecanica. 


\section{INTRODUÇÃO}

As medidas adotadas por empresas para evitar impactos ambientais decorre das pressões da sociedade, consumidores, governo e outras organizações (BERTOLINI et al., 2012). Adotar uma postura pró ativa em relação ao meio ambiente é considerada uma vantagem competitiva para as empresas (BERTOLINI et al., 2013).

As empresas que atuam com serviços que causam impacto ambiental tendem a destinar uma maior parcela da receita à preservação, melhoria e reparo do meio ambiente. Sofrem maior pressão do meio de atuação, e consequentemente, investem mais para compensar danos, garantindo a legitimidade social (MACHADO et al., 2011).

A melhoria da imagem da organização, diferenciação dos concorrentes, concorrência acirrada, e mudanças nas atitudes de compra dos consumidores são algumas razões ligadas ao mercado que levam as empresas a adotar medidas e ações ligadas ao meio ambiente (BERTOLINI et al., 2012). Dependendo do ramo de atuação, investir no verde trata-se de um posicionamento ambiental estratégico (ORSATO, 2002).

A frota de automóveis no Brasil possui um crescimento médio de $5 \%$ ao ano (LIMA et al., 2014). Isso eleva a geração de resíduos sólidos a partir da manutenção de veículos em oficinas mecânicas. Assim, os cuidados com o meio ambiente com a gestão adequada é sinal de que a empresa mantém preocupação constante com o meio ambiente e saúde de seus consumidores, com a garantia de recursos naturais às próximas gerações. No entanto, para uma gestão adequada dos resíduos alguns investimentos são necessários. Dessa maneira, a pergunta de pesquisa é: Qual a viabilidade dos investimentos para adequação ambiental em uma oficina mecânica?

A partir desta questão, o objetivo do trabalho é analisar a viabilidade de investimentos em ações ambientais em oficina mecânica do oeste do Paraná. Considera os investimentos necessários para adequar a empresa para além das exigências legais e sua perspectiva de retorno. A partir da importância de ações sustentáveis voltadas a dimensão ambiental que garantam a continuidade e transmissão de uma imagem favorável no mercado.

Além desta introdução, este artigo apresenta o item 2.1 no qual se discute a questão da sustentabilidade, meio ambiente e empresa. No item 2.2 é discutida a análise da viabilidade em ações e produtos ecologicamente corretos. No item 3 são apresentados os procedimentos metodológicos e no item 4 as análises dos resultados da pesquisa. No item 5 se tem as considerações acerca do trabalho.

\section{FUNDAMENTAÇÃO TEÓRICA}

A seguir estão descritos os fundamentos teóricos utilizados no estudo. Primeiramente um apanhado geral sobre a relação entre a sustentabilidade e a as empresas e posteriormente discute-se a viabilidade de investimentos voltados à preservação e manutenção do meio ambiente.

\subsection{Sustentabilidade e Empresas}

O termo sustentabilidade, apesar de amplamente difundido, precisa ser bem qualificado para explicitar exatamente o que se pretende. Ao se avaliar a sustentabilidade sob a ótica empresarial não se pode deixar de remeter ao conceito de desenvolvimento 
sustentável, pois o mesmo leva em consideração o homem, os recursos naturais, as relações sociais e o estado da Arte da tecnologia disponível. Neste sentido, é importante nos reportar à definição de desenvolvimento sustentável apresentada no relatório da World Commission on Environment and Development (UNITED NATIONS, 1987, p. 24):

\begin{abstract}
Humanity has the ability to make development sustainable to ensure that it meets the needs of the present without compromising the ability of future generations to meet their own needs. The concept of sustainable development does imply limits - not absolute limits but limitations imposed by the present state of technology and social organization on environmental resources and by the ability of the biosphere to absorb the effects of human activities. But technology and social organizations can be both managed and improved to make way for a new era of economic growth.
\end{abstract}

Sob esta ótica, Elkington (2004), propôs o estudo da sustentabilidade baseado no tripé: "prosperidade econômica, qualidade ambiental e justiça social". Visando garantir condições econômicas, benéficas para a sociedade e com utilização racional e consciente dos recursos naturais. Garantindo continuidade para as gerações futuras. Para Sachs (2008) o tripé do desenvolvimento deve ser includente (ter relevância social), com prudência ecológica e viabilidade econômica (sustentado).

Por outro lado, Tripathi et al. (2013) tecem uma crítica ao The triple bottom line, pois acreditam os autores que não existe a possibilidade de um balanceamento entre as três dimensões propostas. Ou seja, empresas que se utilizam de tal "jargão", o fazem apenas como marketing, não tendo sido apresentado métodos capazes de mensurar o que se tira da natureza e o que se devolve para ela. Para exemplificar a incapacidade de mensuração, os autores citam o exemplo da Coca-cola, cujo lema é a sustentabilidade, mas, no entanto, utiliza-se de oito garrafas de água para produzir uma garrafa de bebida.

O comprometimento da gestão com sustentabilidade é importante em todos os segmentos econômicos e empresariais, algumas áreas/setores possuem desafios maiores, conforme a natureza produtiva (KNEIPP et al., 2012). Existe uma relação intrínseca entre o conceito de sustentabilidade e a questão da responsabilidade social por meio de ações que visam elevar a produtividade, melhorar os produtos e gestão, contribuindo para a preservação do meio ambiente. A sustentabilidade em empresas é um tema frequentemente vinculado ao próprio desenvolvimento sustentável (TUPY, 2008).

A adoção de ações sustentáveis só é aplicada quando ocorrem exigências legais, ou por necessidade de certificações (KNEIPP et al., 2012). Trata-se de uma discussão em relação à visão de mundo compartilhada, predominantemente antropocêntrica, onde a natureza é vista unicamente como fonte de recursos e local para destinação de recursos. Que resulta no agravamento de problemas socioambientais. Em algumas empresas a sustentabilidade é associada com a permanência e sobrevivência da própria empresa, dissociada das funções sociais e ambientais (SILVA, et al., 2011).

O consumo e desenvolvimento sustentável são questões amplamente discutidas pelas organizações. Souza (1993) aponta que os princípios do desenvolvimento sustentável são compatíveis com o lucro, e também representa novas oportunidades de negócios. De acordo com Silva et al. (2011) ao analisar empresas do setor de energia elétrica, não se observa uma mudança da visão individualista de sustentabilidade, associada ao objetivo central indexado ao crescimento, à rentabilidade, à liderança, à inovação ou às boas práticas 
de governança corporativa. Assim, não se trata apenas de atender à legislação ambiental, mas de comprometer-se com um desenvolvimento sustentável.

A relação entre meio ambiente e empresa é discutida no sentido da regulamentação existente e conscientização em relação ao uso dos recursos (BÁNKUTI; BÁNKUTI, 2014; MACHADO et al., 2011). A questão ambiental também está atrelada ao desenvolvimento e inovação de produtos e processos em empresas. Além disso, o papel do governo no incentivo e condução de melhorias ambientais é relevante, com políticas, regulamentações e coordenação de ações ambientais (BÁNKUTI; BÁNKUTI, 2014).

Impactos ambientais associados às atividades empresariais podem resultar na descontinuidade de atividades, além de gerar problemas à saúde do homem, dependendo da atividade executada pela organização (VOSS et al., 2014).

Kneipp et al. (2012) em estudo realizado com empresas do setor mineral concluiu que em relação ao contexto do meio ambiente, as empresas possuem atitude reativa. Voltado ao atendimento de exigências legais e mercadológicas. Investem apenas em certificações e algumas práticas de gestão.

No estudo realizado por Bánkuti e Bánkuti (2014) realizado no setor de cosméticos as principais dificuldades em realizar melhorias nas questões ambientais estão associadas ao alto investimento necessário. Os investimentos de melhoria de produtos e processos e conhecimento técnico e científico estão dentre as dificuldades.

De acordo com Melo (2014, p. 100) "os investimentos em programas ambientais e sociais se tornou comum entre as companhias, pois um desenvolvimento empresarial sustentável é parte integrante de um desempenho financeiro próspero".

Sobre a temática do meio ambiente e as empresas, Souza (1993) já destacava que o meio ambiente passou a ter grande relevância nas estratégias empresariais. As empresas na década de 90 descobriram que não agredir o meio ambiente é economicamente viável. Há como alcançar o desenvolvimento sustentável obtendo lucratividade nos negócios.

O investimento das empresas no meio ambiente é considerado uma vantagem competitiva (BERTOLINI et al., 2013; FLORES, 2009; PAGELL et al., 2004). Investimentos em gestão ambiental podem alavancar o desempenho. A criação de produtos e processos limpos requer maneiras novas e inovadoras para produzir (PAGELL et al., 2004).

\subsection{Análise de Viabilidade em Ações e Produtos Ecologicamente Corretos}

A análise de investimentos é imprescindível nas organizações que possuem projetos alternativos de melhoria, assim como os investimentos ambientais. Sendo necessário avaliar se o investimento realizado proporcionará a empresa um retorno esperado (BERTOLINI et al., 2012).

Em um estudo sobre a viabilidade de produtos orgânicos, realizado por Debastiani et al. (2014), ficou demonstrado que os consumidores valorizam o produto saladas orgânicas, mas o retorno não cobria os custos adicionais do investimento. No estudo realizado por Bertolini et al. (2013), também houve inviabilidade na oferta de alho triturado com característica orgânica, uma vez que os valores que os consumidores estavam dispostos a pagar não cobriam os custos operacionais e de matéria prima.

Algumas pesquisas apresentam que a sociedade está disposta a pagar mais por produtos ambientalmente corretos. A partir desta perspectiva que Bertagnolli (2006) buscou avaliar se as empresas estavam obtendo retorno dos investimentos, a partir da influência na 
receita líquida e resultado operacional. Identificou que a variável ambiental está presente entre os fatores de influência.

Um estudo que utiliza o modelo Bertolini et al. (2012) foi aplicado por Barboza et al. (2014) e concluiu que consumidores estavam dispostos a pagar mais por produtos orgânicos, permitindo indicar o aumento no custo dos produtos de uma indústria de cereais. Resultando em sugestão sobre a inclusão de mais uma linha de produtos à empresa.

Em estudo realizado por Massi et al. (2009) foi identificado que os consumidores pesquisados tinham disposição para pagar mais e contribuir financeiramente para a preservação do meio ambiente. Como o percentual de variação representou um valor baixo, houve aceitação por parte dos clientes.

\section{PROCEDIMENTOS METODOLÓGICOS}

Este trabalho foi realizado por meio de diagnóstico organizacional voltado às necessidades de investimentos ambientais em uma oficina mecânica da região oeste do Paraná. Portanto, utilizou-se a pesquisa descritiva (BEUREN et al., 2009) com o objetivo de descrever a situação atual e ações de melhoria na gestão dos resíduos.

Foi utilizada abordagem qualitativa na caracterização da empresa e análise das necessidades de investimentos. A abordagem quantitativa ocorreu em relação à aplicação do modelo de Bertolini et al. (2012) para testar a viabilidade financeira do projeto. Considerando que a pesquisa qualitativa complementa a quantitativa (BEUREN et al., 2009).

Trata-se de um estudo de caso único, em uma unidade que se analisa profundamente o ambiente da empresa e suas necessidades de adequações (STAKE, 2005; GODOY, 1995). Visando um exame detalhado do ambiente, analisando intensivamente.

Foram realizadas três visitas (março, abril e Junho) e uma entrevista com o proprietário da organização no período de março a julho de 2015 para obtenção de dados. A entrevista foi organizada de forma semiestruturada, gravada e transcrita na íntegra para análise. O roteiro de entrevista abordou as seguintes informações: histórico empresarial; principais atividades e serviços; principais ações já executadas; projetos em execução; resíduos e tipos de materiais gerados; estratégias de redução de custos; análise das possibilidades de investimentos e estudo dos custos de execução.

O software Atlas.ti proporcionou a organização dos resultados do diagnóstico e entrevista em códigos, com a relação dos investimentos. Durante o processo foi identificado que a empresa realizou durante o mês de julho 25 ordens de serviço (atendeu 25 clientes), e possui um faturamento médio mensal de $\mathrm{R} \$ 45.000,00$ (quarenta e cinco mil reais), informações que serviram de base para a etapa de análise. Foram elencados os principais investimentos necessários e o valor necessário para adequação.

Após o diagnóstico ocorreu aplicação de formulário de coleta (presencial) para análise do percentual que os consumidores estavam dispostos a pagar por serviços oferecidos em oficina ambientalmente correta, visando à informação necessária para subsidiar a análise do investimento. A base desta pesquisa utilizou apenas uma questão do formulário: "Assinale a porcentagem que você estaria disposto a pagar a mais do que normalmente paga, para utilizar os serviços de uma oficina mecânica ambientalmente correta, que realiza o tratamento adequado de seus resíduos?" As opções eram: 0\%, 5\%, $10 \%, 15 \%$ ou $20 \%$. A aplicação ocorreu no mês de agosto de 2015 e contemplou 51 potenciais clientes, quantidade superior a média de 25 atendimentos efetuados pela empresa. 
Optou-se por aplicar com clientes potenciais por se tratar de clientes localizados na maioria em bairros próximos a empresa, sem identificar a organização, visando obter informações com pouca tendência ao viés. Para obter as 51 respostas foram distribuídos 60 formulários durante a tarde do dia 27 de julho de 2015. Foram entregues por bairro (A, B e C) por dois pesquisadores, e recolhidos dentro do prazo de uma hora para resposta, apesar disso, 9 formulários retornaram em branco. A distribuição ocorreu de forma não probabilística por conglomerado. Os formulários foram entregues nos bairros próximos à localização da oficina, onde está a maioria dos clientes principais. Na tabulação dos dados foi utilizado o software Microsoft Office Excel.

Para análise de viabilidade, foi adaptado o modelo proposto por Bertolini et al. (2012). Dividido originalmente em seis etapas:

1 - Identificação do valor para os consumidores dos produtos ecológicos, com base nas respostas e disposição dos consumidores em pagar mais pelo serviço;

2 - Levantamento da previsão da compra do produto ecológico e sua relação de preço, com adaptação do modelo, adequando à previsão diária de incremento de receita;

3 - Identificação da periodicidade de compra e do preço projetado pelos consumidores com base no percentual incremental identificado na pesquisa;

4 - Determinação do volume de investimentos para a fabricação de produtos ecologicamente corretos, considerando o diagnóstico e necessidades de adaptação na empresa;

5 - Projeção do retorno financeiro dos produtos ecologicamente corretos;

6 - Análise da proposta de investimento em produtos ecologicamente corretos. $\mathrm{Na}$ oficina mecânica, foi identificado o percentual que o consumidor estava disposto a pagar e realizada uma previsão diária de receita com base nos dados repassados pela empresa. Permitindo análises sobre o retorno financeiro dos serviços (incluindo payback simples) com a inclusão do percentual aceitável.

Além do cálculo do modelo apresentado, foi realizada uma estimativa temporal de retorno por meio do payback simples. Visando demonstrar o período de retorno básico como opção, podendo ainda ser realizadas outras análises para facilitar na tomada de decisão.

\section{RESULTADOS E DISCUSSÃO}

A empresa pesquisada é classificada como empresa de pequeno porte, localizada no oeste do Paraná. Atua desde 1991 no mercado e presta serviços de revisão em geral, injeção eletrônica, limpeza de bico, regulagens, câmbio e diferencial.

Durante o diagnóstico foi averiguado que a oficina já possuía um projeto de reforma e ampliação. Com isso foi possível descrever ações que estavam incluídas no projeto, e sugerir ações de melhoria em relação à gestão de resíduos sólidos. As ações foram descritas na Figura 1 para compreender todas as ações relacionadas com o objetivo de ter "cuidado com o meio ambiente". 
Figura 1 - Investimentos necessários e perspectivas.

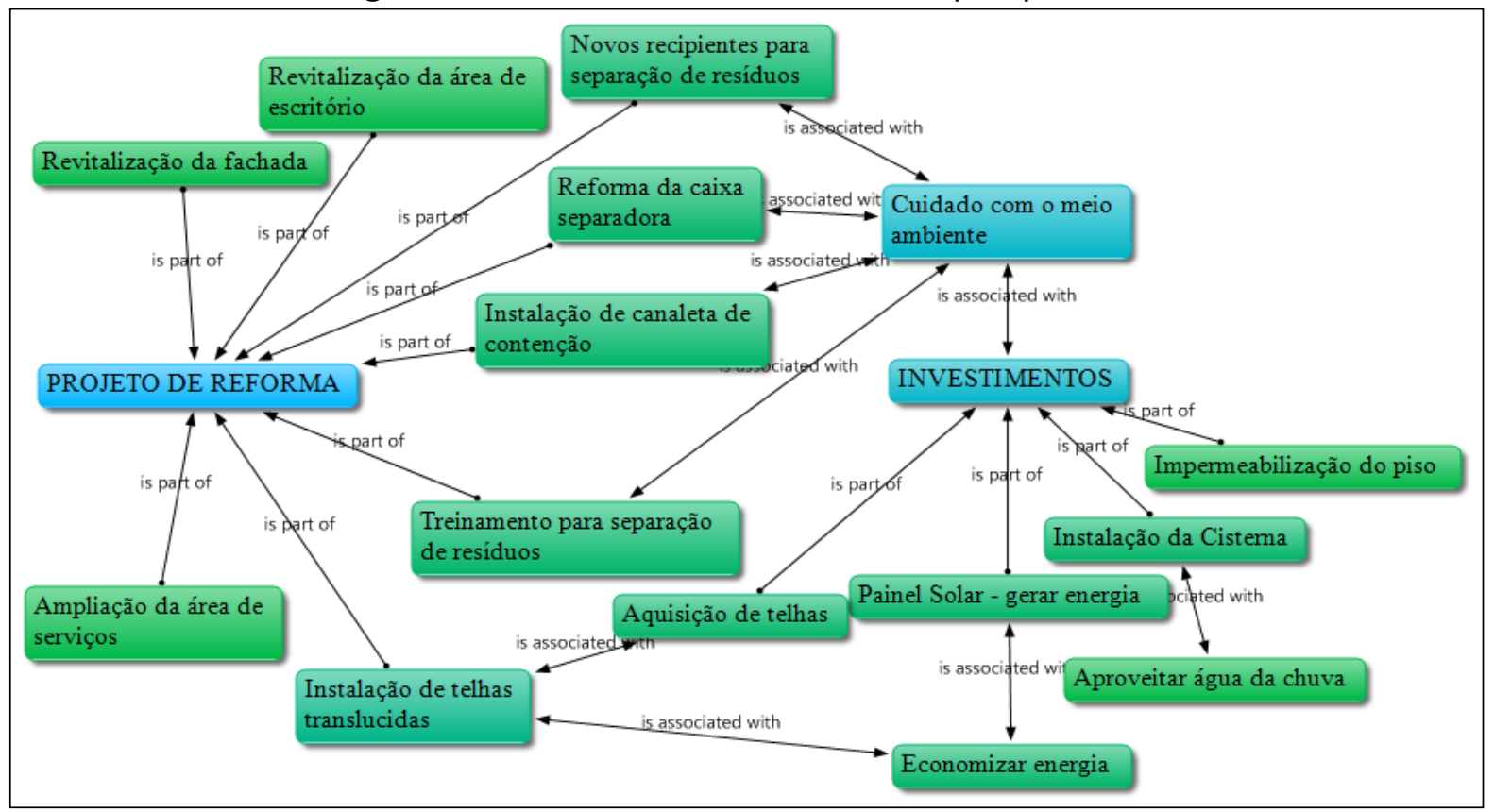

Fonte: Pesquisa aplicada (2015)

Alguns investimentos têm ligação direta com a gestão dos resíduos sólidos: impermeabilização, instalação de canaleta de contenção no piso, reforma da caixa separadora de água e óleo, novos recipientes para separação dos resíduos e treinamento dos funcionários. Estes fazem parte da adequação da empresa ao Plano de Gerenciamento de Resíduos.

A empresa propõe investir em ações que vão além da exigência legal, como a instalação da cisterna para reaproveitar água e compra/ instalação de telhas translucidas para melhorar a iluminação interna. Além do painel solar que permitirá economia, produção e estoque de energia junto à rede.

O diagnóstico na oficina mecânica resultou na Tabela 1 com os valores necessários para realizar as adequações.

Tabela 1 - Investimentos necessários.

\begin{tabular}{|c|c|c|c|c|}
\hline ESTRATÉGIA & PRODUTO & CUSTO R\$ & QUANT. & TOTAL \\
\hline \multirow[t]{2}{*}{$\begin{array}{l}\text { Impermeabilizaç } \\
\text { ão do piso }\end{array}$} & $\begin{array}{l}\text { Real Impermeabilizante Color } 18 \mathrm{I} \text { - a base de } \\
\text { solvente. } 01 \text { unid. } \\
+ \text { Thinner Car Paint 5lts. }\end{array}$ & 549,00 & 1,00 & 549,00 \\
\hline & Mão de obra - aplicação - aprox. 380 m² & 12,00 & 380,00 & 4560,00 \\
\hline $\begin{array}{l}\text { Telhado - telhas } \\
\text { translucidas. }\end{array}$ & $\begin{array}{l}\text { Telha Transparente Fortlev Fibra 2,44x1,10 } \\
6 \mathrm{MM} .01 \text { unid. }\end{array}$ & 58,10 & 10,00 & 581,00 \\
\hline \multirow{2}{*}{$\begin{array}{l}\text { Instalação de } \\
\text { cisterna para } \\
\text { aproveitamento } \\
\text { de água. }\end{array}$} & $\begin{array}{l}\text { Tanque Polietileno Fortlev } 1750 \text { Its - } \\
\text { completo. } 01 \text { unid. }\end{array}$ & 744,35 & 1,00 & 744,35 \\
\hline & Instalação - Mão de obra & 200,00 & 1,00 & 200,00 \\
\hline $\begin{array}{l}\text { Aproveitamento } \\
\text { de energia solar. }\end{array}$ & $\begin{array}{l}\text { - reduzir o consumo de energia elétrica para } \\
\text { a empresa; } \\
\text { 10 Primeira opção Master Solar - Cascavel - } \\
\text { Conjunto completo instalado com projeto na }\end{array}$ & $\begin{array}{l}1020.000,00 \\
2 \text { ㅇ } 20.947,00\end{array}$ & 1,00 & 20000,00 \\
\hline
\end{tabular}




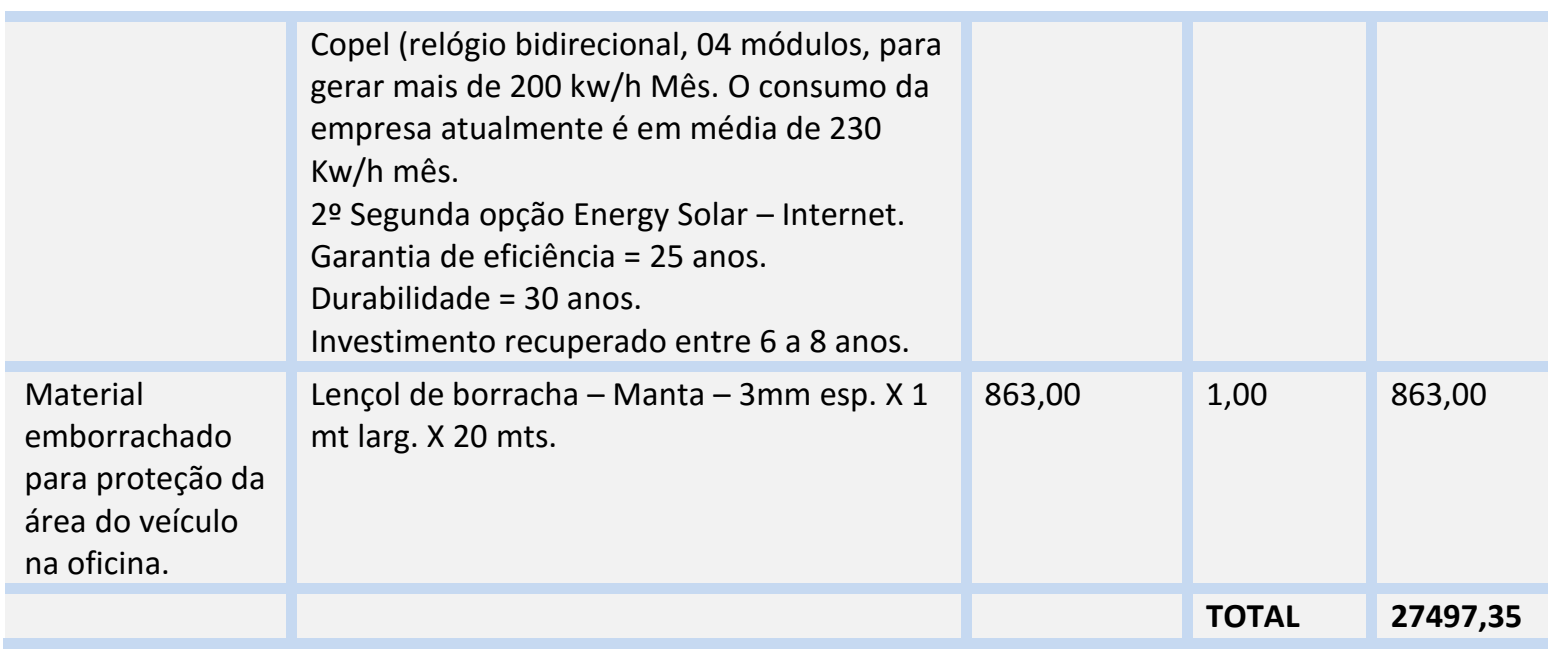

Fonte: Pesquisa aplicada (2015).

Além da proposta de investimentos, houve a sugestão para a empresa pela adoção do Selo Verde Sindirepa - PR. Para obter o Selo Verde a empresa terá um custo de até R\$ 130,00 mensais, com assessoria jurídica do sindicato.

O investimento inicial básico para adequações, sem considerar o investimento no painel solar é de $\mathrm{R} \$ 7.497,35$. De acordo com a empresa MasterSolar o investimento de $\mathrm{R} \$$ 20.000,00 em um painel solar possui um retorno médio de investimento entre 6 e 8 anos. Dependendo da produtividade de energia elétrica.

Dados da instituição apontam que no mês de julho/2015 houve a emissão de 25 ordens de serviços prestadas. A média de vendas mensal da empresa atinge $\mathrm{R} \$ 45.000$ (quarenta e cinco mil reais). Estas informações foram úteis para adaptação e verificação da viabilidade.

Para uma análise sobre a viabilidade do investimento, o modelo de Bertolini et al. (2012) foi adaptado.

Na pesquisa com 51 clientes potenciais da empresa, foi perguntado qual percentual estaria disposto a pagar a mais por serviços de uma oficina mecânica ambientalmente correta. Os resultados demonstraram que $35 \%$ não está disposto a pagar, e no máximo, a empresa poderá incluir 5\% sobre os valores de venda (29\%).

Tabela 2 - Disposição para pagar mais.

\begin{tabular}{|l|r|r|}
\hline & & \multicolumn{2}{c}{$\begin{array}{l}\text { Qual a porcentagem que você estaria disposto a pagar a mais do que } \\
\text { normalmente paga, para utilizar os serviços de uma oficina mecânica } \\
\text { QUANT. }\end{array}$} & ambientalmente correta, que realiza o tratamento adequado de seus resíduos? \\
\hline $0 \%$ & 18 & $35,29 \%$ \\
\hline $5 \%$ & 15 & $29,41 \%$ \\
\hline $10 \%$ & 8 & $15,69 \%$ \\
\hline $15 \%$ & 8 & $15,69 \%$ \\
\hline $20 \%$ & 2 & $3,92 \%$ \\
\hline Total Geral & 51 & $100,00 \%$ \\
\hline
\end{tabular}

Fonte: Pesquisa aplicada (2015).

Considerando que a média de serviços prestados pela empresa gera um retorno médio diário de $\mathrm{R} \$ 2045,00$ (atuando em média 22 dias úteis/mês). A proposta de inclusão 
de $5 \%$ no retorno resulta em $\mathrm{R} \$ 66,46$ de incremento diário na receita. Considerando que $65 \%$ (33) dos clientes possuem disposição para pagar $5 \%$ ou mais.

Aplicando o modelo de Bertolini et al. (2012) adaptado, foram realizadas 4 etapas:

1o etapa: P.P - (P.A. + C.D.) = P.V.un

Onde: P.P. = Preço Projetado; P.A. = Preço Atual praticado pela organização; C.D. = Custos Diretos do produto ecológico; e P.V.un. = Projeção da Valorização Unitária.

Cálculo com valores/dia. Projetado - atual = Projeção da Valorização Diária.

Resultados: $2.111,46-2.045,00=66,46$ Dia

2o etapa:

P.V.un $\times$ Q.C.I. $\times \mathrm{N}=$ P.V.T.p

Onde: P.V.un. = Projeção da Valorização Unitária; Q.C.I. = Quantidade de Consumo Individual; $\mathrm{N}=$ Número de consumidores da organização; e P.V.T.p. = Projeção da Valorização Total periódica.

A fórmula foi adaptada, resultando nos seguintes cálculos: Projeção da Valorização Diária $X$ Número de dias de efetivo exercício = Projeção da receita incremental.

Resultados: 66,46 x $22=1.462,12$ (mês).

3o etapa:

P.V.T.m. $\times \frac{1-(1+1)^{-n}}{\mathrm{i}}=$ P.V.T.des.

Onde: P.V.T.p. = Projeção da Valorização Total periódica $(1.462,12) ; \mathrm{n}=$ Período do projeto (24); i = Taxa do custo do capital ou da rentabilidade mínima exigida $(0,05)$; e P.V.T.des. = Projeção da Valorização Total do Período Descontado.

Aplicando na fórmula:

$1.462,12 \times[1-(1+0,05)-24 / 0,05]=$

Resultados: $1.462,12 \times 13,798=20.175,27$

4ㅇ etapa:

Após, foi dividida a projeção no período pelo investimento:

$$
\frac{\text { P.V.T.des. }}{\text { IP.E }}=\text { R.F.R\$in. }
$$

I.P.E.

Onde: P.V.T.des. = Projeção da Valorização Total do Período Descontado; I.P.E. = Investimento para formar o Produto Ecológico; e R.F.R\$ in. = Retorno Financeiro Projetado para cada R\$ Investido.

Resultados: $20.175,27 / 7497,35=2,69$ (R.F.R\$ in.).

Para cada $R \$$ investido existe um retorno de $R \$ 2,69$. Significa que investindo nas adaptações voltadas à gestão adequada dos resíduos, sem considerar a instalação do painel solar, a empresa terá o devido retorno para uma aplicação do projeto, considerando 24 meses.

A partir dos resultados é possível realizar a análise proposta por Bertolini et al. (2012) descrita na Tabela 3. 
Tabela 3 - Proposta de análise.

\begin{tabular}{|r|r|}
\hline $\begin{array}{c}\text { Situação do retorno projetado para cada R\$ } \\
\text { investido }\end{array}$ & Viabilidade do investimento \\
\hline R.F.R\$ in. $<1$ & Não há viabilidade financeira no investimento. \\
\hline R.F.R\$ in. $=1$ & Ponto de Equilíbrio do Investimento. \\
\hline R.F.R\$ in. $>1$ & Há viabilidade financeira no investimento. \\
\hline
\end{tabular}

Fonte: Bertolini et al. (2012, p. 586).

A partir da análise, é possível concluir que o projeto possui viabilidade financeira no investimento.

Calculando o Payback Simples para o investimento de $\mathrm{R} \$ 7497,35$, com uma média de entrada de caixa diária de $R \$ 2045,00$, e um incremento de $R \$ 66,46 /$ dia $\times 22$ dias de trabalho mensais $=\mathrm{R} \$ 1.462,12$. O aumento no preço de $5 \%$ leva a empresa a obter um incremento de $\mathrm{R} \$ 1.462,12$ por mês.

Cálculo Payback $=7.497,35 / 1.462,12=5,13$ meses.

Cálculo diário $=7.497,35-(5 \times 1.462,12)=186,75 / 66,46=2,80$ (3 dias).

Recuperação do valor investido em 5 meses e 3 dias de exercício. E se a empresa incluir o valor referente ao painel solar no cálculo payback, o investimento de 27.497,35 seria recuperado em 18 meses e 18 dias. Sem considerar que, ao instalar um painel solar terá redução considerável nos custos com energia elétrica, ao pagar apenas a taxa mínima.

\section{CONSIDERAÇÕES FINAIS}

Investir em ações ambientais nas empresas não é problema para os gestores, trata-se de um desafio que exige tempo, dedicação e aperfeiçoamento profissional. A concepção sobre a importância de gerir os resíduos em oficinas mecânicas e utilizar ações ambientais de prevenção aos danos é vista como essencial pela empresa pesquisada. Para as empresas o investimento está muito ligado ao retorno, seja em economia ou visibilidade organizacional da instituição como ambientalmente correta.

Os resultados comprovam que adequações ambientais podem ser realizadas, desde que os consumidores estejam dispostos a pagar a mais. No entanto, outros fatores precisam ser considerados pelo fato da possibilidade de atrair mais consumidores que valorizam as questões ambientais.

Os resultados indicam viabilidade do investimento, incluindo-se $5 \%$ de margem sobre o preço dos serviços prestados. A cada real investido a empresa terá um retorno de $\mathrm{R} \$ 2,69$, indicando que o projeto pode ser executado pela organização.

A pesquisa com o público consumidor indicou que ainda há uma rejeição em pagar mais por parte de $35,29 \% \%$ dos consumidores. Neste caso a empresa pode adequar ações de marketing integradas à imagem de instituição consciente para ressaltar a importância de suas ações para o meio ambiente. De modo geral, assim como também concluíram Alves e Freitas (2013), são necessários maiores esclarecimentos às organizações e consumidores sobre o que de fato deve ser considerado um produto ou serviço ecologicamente correto (verde), além disso, evitar o apelo ambiental com propósito ludibriante.

Este estudo não pode ser generalizado, visto que adequações ambientais dependem de cada caso. Estudos futuros podem ser realizados sobre a percepção do consumidor em relação às questões ambientais em oficinas mecânicas. Além de outras adaptações do modelo para oficinas de grande porte. 


\section{REFERÊNCIAS}

ALVES, I. J. B. da R.; FREITAS, L. S. de. O Produto Verde é Sempre "Verde"? Uma Análise do Bloco Cerâmico a partir do Ecodesign. Revista de Administração, Contabilidade e Sustentabilidade - REUNIR, v. 3, n. 1, 2013, pp. 1-20.

BÁNKUTI; S. M. S.; BÁNKUTI, F. I. Gestão ambiental e estratégia empresarial: um estudo em uma empresa de cosméticos no Brasil. Revista de Gestão \& Produção, São Carlos, v. 21, n. 1, 2014, pp.171-184.

BARBOZA, J. V. S., et al. Análise da disposição de consumo por orgânicos em uma indústria de cereais. In: III SIMPÓSIO INTERNACIONAL DE GESTÃO E PROJETOS, INOVAÇÃO E SUSTENTABILIDADE, São Paulo, SP, Brasil. Anais... São Paulo, SP: 09 a 11 de novembro de 2014, pp. 1-16.

BERTAGNOLLI, D. D. de O. Estudo sobre a influência dos investimentos sociais e ambientais no desempenho econômico das empresas. Dissertação de mestrado. Universidade do Vale do Rio dos Sinos - UNISINOS, São Leopoldo, RS, Brasil, 2006.

BERTOLINI, G. R. F. et al. A viabilidade financeira no desenvolvimento de produtos ecológicos valorizados pelos consumidores. Revista de Gestão e Projetos-GeP, São Paulo, v. 4, n. 3, 2013, pp. 01-29.

BERTOLINI, G. R. F.; ROJO, C. A.; LEZANA, Á. G. R. Modelo de análise de investimentos para fabricação de produtos ecologicamente corretos. Revista de Gestão \& Produção, São Carlos, v. 19, n. 3,2012 , pp. 575-588.

BEUREN, I. M. (Org.). n/a et al. Como elaborar trabalhos monográficos em contabilidade (3a ed). São Paulo: Atlas, 2009.

DEBASTIANI, S. M., et al. Análise da viabilidade econômica na oferta de saladas orgânicas em restaurantes. In: III SIMPÓSIO INTERNACIONAL DE GESTÃO E PROJETOS, INOVAÇÃO E SUSTENTABILIDADE, São Paulo, SP, Brasil. Anais... São Paulo, SP: 09 a 11 de novembro de 2014, pp. 1-16.

ELKINGTON, J. Enter the Triple Bottom Line. In: A. Henriques \& J. Richardson (Eds.). The Triple Bottom Line: Does it All Add Up? Assessing the Sustainability of Business and CSR (pp. 1-16). London: Earthscan Publications, 2004.

FLORES, G. S. da S. Análise da relação entre investimentos ambientais e desempenho econômico. Dissertação de mestrado. Programa de Pós-Graduação em Ciências Contábeis. Universidade do Vale do Rio dos Sinos - UNISINOS, São Leopoldo, RS, Brasil, 2009, p. 96.

GODOY, A. S. Pesquisa qualitativa: tipos fundamentais. Revista de Administração de Empresas, v. 35, n. 3, 1995, pp. 20-29.

KNEIPP, J. M., et al. Gestão para a sustentabilidade em empresas do setor mineral. Revista de Ciências de Administração, v. 14, n. 33, 2012, pp. 52-67. 
LIMA, T. L. de A., et al. Diagnóstico de inovação no setor da indústria de reparos de automóveis usando o característico de inovação setorial. Revista Exacta - EP, v. 12, n. 2, 2014, pp. 231-240.

MACHADO, M. R.; MACHADO, M. A. V.; MURCIA, F. D. R. Em busca da legitimidade social: relação entre o impacto ambiental da atividade econômica das empresas brasileiras e os investimentos no meio ambiente. Revista Universo Contábil, v. 7, n. 1, 2011, pp. 20-35.

MASSI, K. G., et al. Valoração contingente de uma oficina mecânica no município de Osasco, SP. Revista Científica Hermes, v. 1, n. 1, 2009, pp.42-48.

MELO, M. M. D. de. Divulgação de informações da sustentabilidade empresarial e sua relação com os investimentos socioambientais e a governança corporativa das empresas listadas no índice de sustentabilidade empresarial (ISE) da BM\&FBOVESPA. Dissertação de mestrado. Programa Multi-institucional e Inter-Regional de Pós-Graduação em Ciências Contábeis. Universidade Federal do Rio Grande do Norte, Natal, RN, Brasil, 2014, p. 118.

ORSATO, R. J. Posicionamento ambiental estratégico: identificando quando vale a pena investir no verde. Revista Eletrônica de Administração - REAd, v. 8, n. 6, 2002, pp. 1-29.

PAGELL, M., et al. Does the competitive environment influence the efficacy of investments in environmental management?. The Journal of Supply Chain Management, v. 17, n. 19, 2004, pp. 30-39.

SACHS, I. Desenvolvimento: Includente, Sustentável, Sustentado. Rio de Janeiro: Garamond, 2008.

SILVA, S. S. da.; REIS, R. P.; AMÂNCIO, R. Paradigmas ambientais nos relatos de sustentabilidade de organizações do setor de energia elétrica. Revista de Administração Mackenzie-RAM, v. 12, n. 3, 2011, pp. 146-176.

SOUZA, M. T. S. de. Rumo à prática empresarial sustentável. Revista de Administração de Empresas, v. 33, n. 4, 1993, pp.40-52.

STAKE, R. E. Qualitative Case Studies. In: DENZIN, N; LINCOLN, Y. Handbook of qualitative research (pp. 443 -466). London: Sage, 2005.

TUPY, O. Investimentos em meio ambiente, responsabilidade social e desempenho econômico-financeiro de empresas no Brasil. Revista de Estudos Politécnicos, v. 6, n. 10, 2008, pp.73-86.

VOSS, B. de L., et al. Evidenciação ambiental dos resíduos sólidos em companhias abertas no Brasil potencialmente poluidoras. Revista Contabilidade Financeira - USP, v. 24, n. 62, 2013, pp.125-141.

TRIPATHI, D. K.; KAUSHAL, A.; SHARMA, V. Reality of Triple Bottom Line. Global Journal of Management and Business Studies, v. 3, n. 2, 2013, pp.153-158. 